\title{
ANTECEDENTS OF ONLINE PURCHASE INTENTION AND BEHAVIOUR: UNCOVERING UNOBSERVED HETEROGENEITY
}

\author{
Joaquim SILVA $^{*}$, José Carlos PINHO ${ }^{(\mathbb{D}}$, Ana SOARES ${ }^{(\mathbb{D})}$, \\ Elisabete SÁ \\ School of Economics and Management, University of Minho, Braga, Portugal
}

Received 25 April 2018; accepted 24 October 2018

\begin{abstract}
The paper aims at exploring the antecedents of customers' online purchase intention and behaviour, and at uncovering sources of heterogeneity. A sample of customers was surveyed to measure perceived risk and benefits, trust, online purchase intention and behaviour. The study confirmed the causal chain of perceived risks-trust-perceived benefits-online purchase intentionactual purchase. A Finite Mixture Partial Least Squares (FIMIX-PLS) was performed to uncover sources of heterogeneity. It found that the level of security of the payment methods is relevant to understand the relationship between purchase intention and behaviour, while the level of previous experience with the online medium clarifies the relationship between perceived risk and trust. The study contributes to understanding the antecedents of online purchase intention and their relationship with actual purchase behaviour. Additionally, it offers evidence of heterogeneity in the proposed causal relations, particularly, concerning the level of trust in the payment methods and the level of Internet experience.
\end{abstract}

Keywords: online purchase intention, online purchase behaviour, perceived risk, trust, perceived benefits, unobserved heterogeneity, online payment methods, level of Internet experience, FIMIXPLS.

JEL Classification: L81, M31.

\section{Introduction}

Online shopping has been increasing worldwide. The percentage of individuals from OECD (Organisation for Economic Co-operation and Development) countries that have purchased online during 2016 was around 53\% (OECD, 2018). Recognising an opportunity in this trend, suppliers are increasingly including the Internet in their distribution strategies. Depending on the conditions of demand and the level of Internet acceptance, a dual channel structure, integrating offline and online, can, indeed, yield both manufacturers and retailers

*Corresponding author. E-mail: josilva@eeg.uminho.pt 
competitive advantage (Zhang, Zhang, Mizgier, \& Zhang, 2017). There are notable differences between online and offline shoppers, however (Arce-Urriza, Cebollada, \& Tarira, 2017; Díaz, Gómez, \& Molina, 2017) as well as variations among online consumers. Research shows that intention to purchase, repurchase and loyalty are associated with perceptions of the value of the online channel (Molinillo, Gómez-Ortiz, Pérez-Aranda, \& Navarro-García, 2017; Wu, Chen, Chen, \& Cheng, 2014). Recent studies have considered the effect of perceived benefits, such as convenience, cost-effectiveness and variety, along with perceived risks and trust on the online shopping environment (Sharma, Menard, \& Mutchler, 2017; Zhang et al., 2017).

Some research has focused on countries where online shopping is less developed, allowing a more comprehensive, diverse and contextualised knowledge on the topic (Agag \& ElMasry, 2017; Al-Debei, Akroush, \& Ashouri, 2015; Escobar-Rodríguez \& Bonsón-Fernández, 2017). This paper assumes a similar approach and focuses on Portugal, which has been having a slow online purchase growth, over the last years, compared to other OECD countries. The study takes a step further by looking at both intention and actual behaviour as outcomes of perceived risk, trust and benefits of online purchase. Although intention has been considered a good predictor of behaviour, data may not always confirm this assumption, so these two variables should be studied together (Sharma et al., 2017).

The study also contributes to exploring the effect of trust on perceived benefits of online purchase. While the impact of trust on the perceived value of online shopping has been studied (Ponte, Carvajal-Trujillo, \& Escobar-Rodríguez, 2015), the effect of trust on perceived benefits is not clear. Some research suggested the contrary effect, by conceptualising online shopping positive features as antecedents of trust (e.g. Bilgihan, 2016; Kim, Chung, \& Lee, 2011; Molinillo et al., 2017). Some research establishes the trust-perceived benefits relationship but applying the concept of perceived risk instead of trust. Hubert, Blut, Brock, Backhaus, and Eberhardt (2017), for example, concluded that different types of risk are predictors of usefulness perceptions of mobile shopping, studied as a measure of helpfulness and convenience, which other studies include as one of the measures of the perceived benefits construct (Al-Debei et al., 2015; Zhang et al., 2017). Furthermore, Pappas (2017a) found that the relationship between the perception of risks and benefits is reciprocal. In what concerns trust, a more in-depth knowledge about its effect on perceived benefits has not yet been attained. However, this is a salient factor with known effects on the proliferation of Internet shopping (Chien, Chen, \& Hsu, 2012).

Thus, the purpose of this paper is to clarify the effect of trust on the perceived benefits of online shopping, while exploring the importance of the perceived risk as a predictor of trust in the online channel, so as to clarify the antecedents of both online shopping intention and behaviour. Additionally, it aims at identifying effects of heterogeneity in the model, by exploring variations associated with characteristics of the sample and perceptions about the level of trust in payment methods.

This paper is structured as follows: firstly, the review of the literature is presented. Then, the research method used in the study is put forward, followed by research findings and discussion. Finally, conclusions are offered. 


\section{Literature review}

\subsection{Perceived risk, trust and online purchase intention}

Online purchasing can be hindered by the lack of direct interaction with the product and seller, leading to a higher feeling of insecurity and perceived risk (Kim, Ferrin, \& Rao, 2008; Nepomuceno, Laroche, \& Richard, 2014). Traditional research has focused mostly on perceived risk, rather than on actual risks, and has addressed specific products, services, or buying situations (Jasper \& Ouellette, 1994; Stone \& Grønhaug, 1993). More recently, with the rise of online shopping and service delivery, perceived risk became a key issue for online behaviour (Mou, Shin, \& Cohen, 2017; Pappas, 2017b; Zhou, Dai, \& Zhang, 2007). Some of these risks are related to personal data and financial transactions security, whereas others include the performance of the product and the fear of buying fake or smuggled products, and of wasting money and time unwisely (Chen, Yan, Fan, \& Gordon, 2015; Hubert et al., 2017; Nepomuceno et al., 2014; Pappas, 2017a; Ponte et al., 2015). Despite the growth of the research on this topic, previous results are not consistent (Chang \& Chen, 2008; Chang et al., 2005; Mou et al., 2017). Research suggests that it is possible to overcome the online risk barriers if marketers can build enough trust in the channel (Harridge-March, 2006). However, findings are inconsistent concerning the relationship between perceived risk and trust (Hong, 2015). While some studies concluded that trust can be a strong predictor for reducing perceptions of risk (Agag \& El-Masry, 2017; Büttner \& Göritz, 2008), others found the opposite relationship (Pappas, 2017a; Ponte et al., 2015; Sharma et al., 2017). Others, still, propose a reciprocal relationship between the two constructs (Chang \& Chen, 2008; Comegys et al., 2009).

This study builds upon the premise of Corritore et al. (2003), who argue that, when the user has a high perception of control, he/she does not need to trust. However, in the face of high perceptions of risk, when he/she has low levels of control, being able to trust becomes critical to act. Therefore, perceived risk is conceptualised as a predictor of trust (Hong \& Cha, 2013). Understanding trust is, thus, critical to ascertain the potentialities and limits of online purchasing (Clemons et al., 2016). Trust in the online channel has been conceptualised both as a belief, i.e., an expectation about a partner's trustworthiness, and as a behavioural intention or behaviour reflecting a reliance on a partner (Shainesh, 2012). Trust is an essential prerequisite for online purchase intention (Chang \& Chen, 2008; Kim et al., 2008). Research confirms that trust is related to a positive attitude towards online shopping (Al-Debei et al., 2015), influences directly and positively online purchase intention (Ponte et al., 2015; Sharma et al., 2017), and fosters e-loyalty (Bilgihan, 2016; Kim et al., 2011). Following Teo and Liu (2007), trust in the Internet relies on the perception of the risks and benefits associated with transactions. Hence:

H1: The greater the perceived risk, the lower the trust in the Internet.

$\mathrm{H} 2$ : The higher the trust in the Internet, the greater the intention to purchase online. 


\subsection{Perceived benefits and online purchase intention}

The construct of perceived benefits can be viewed as a determinant of the shopping experience, being one of the components of perceived value, which is a trade-off between what is gained and given (Dodds \& Monroe, 1985). It translates into the consumer's subjective belief that he/she will gain something from the Internet purchase (Forsythe et al., 2006). The convenience of shopping in the privacy of home or anywhere and anytime, the possibility to save time and money, accessing a wider selection of products, searching before buying and being able to compare offers are some of the perceived benefits that can influence the online purchase intention, behaviour and loyalty (Fang et al., 2016; Hubert et al., 2017; Pappas, 2017a; Zhang et al., 2017). Online purchasing has utilitarian benefits, but also hedonic value, referring to the enjoyable shopping experience provided by the channel, which can be a strong motivator (Bilgihan, 2016; Childers, Carr, Peck, \& Carson, 2001; Molinillo et al., 2017; Shang, Chen, \& Shen, 2005).

If a higher perception of risk can lead to lower trust in the Internet, the contrary seems to be right regarding perceived benefits. Literature has explored the positive effect of usefulness and perceived benefits as antecedents of trust in the medium (Bilgihan, 2016; Chien et al., 2012). From this work's standpoint, however, the reliance on both the process and the vendor are important for acknowledging the benefits of online purchase (Al-Debei et al., 2015; Mou et al., 2017). Research confirms the positive influence of trust in the perceived value, arguing that if customers trust an online vendor, they will reduce the non-monetary costs and, consequently, they will perceive higher value (Escobar-Rodrígues \& Bonsón-Fernández, 2017; Kim, Xu, \& Gupta, 2012). Hence:

H3: The higher the trust in the Internet, the greater the perceived benefits.

H4: The higher the perceived benefits, the greater the intention to purchase online.

\subsection{Online purchase intention and actual online purchase behaviour}

Studies that have been exploring online purchase intention rely on the assumption that intention predicts behaviour (Chen et al., 2015; Zhou et al., 2007). Such assumption derives from well-established theories and has empirical support (Lin, 2007). However, reliance on intentions to forecast behaviour is not without criticism, since a gap between the two may exist (Sheeran \& Webb, 2016) including systematic biases in reports of stated intentions and shifts in true intentions over time, due to unexpected factors (Sun \& Morwitz, 2010). Consequently, online purchase intention and actual behaviour should be studied simultaneously (Sharma et al., 2017) and the influences on the relationship between intention and actual behaviour offers ground for exploration. Consistent with Li, Kuo, and Rusell (2006) and Verhagen and van Dolen (2009), the frequency of purchase and amount of purchase can be used to capture actual online purchase behaviour on the Internet. Hence:

H5: Intention to purchase has a positive impact on the amount of online purchase.

H6: Intention to purchase has a positive impact on the frequency of online purchase.

The model suggested (Figure 1) lays on the assumption that the sample characteristics can influence the proposed relationships. In fact, previous research exploring the effect of online 


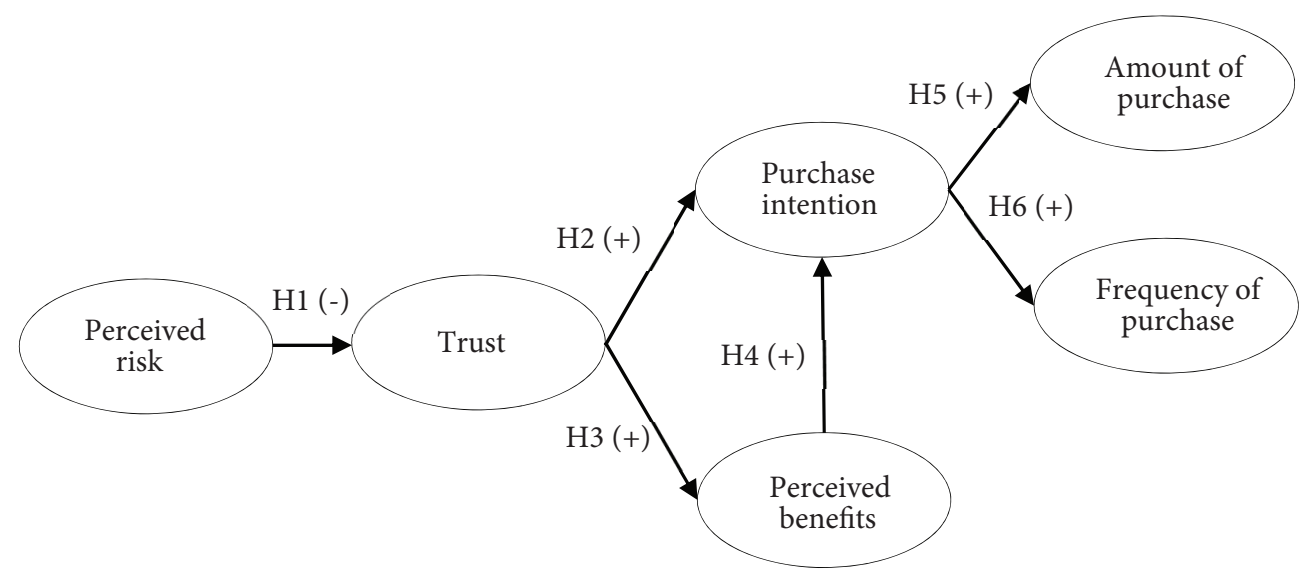

Figure 1. Conceptual model of the antecedents of the purchase behaviour on the Internet

consumers' characteristics found variations in age and gender groups (Chen et al., 2015; Fang, Wen, George, \& Prybutok, 2016; Wu et al., 2014). Studies on the effect of the level of experience and familiarity with the Internet medium are not consistent. While Sharma et al. (2017) concluded that familiarity could lower the perception of risk, Agag and El-Masry (2017) did not find a relationship between the level of consumer experience and website trust. The effects of the level of experience should, therefore, be further explored.

Also, the literature suggests that perceived security, risk and trust are essential factors influencing customer's intention and behaviour in the adoption of online payment methods (C. Kim, Tao, Shin, \& K.-S. Kim, 2010; Yang, Pang, Liu, Yen, \& Michael Tarn, 2015). Trust in online payments is influenced by perceived security (Kim et al., 2010) and perceived risks (Yang et al., 2015). Therefore, it can be expected that gender, level of familiarity or experience with the medium and level of trust in the payment methods will contribute to explain some heterogeneity in the proposed relationships.

\section{Methodology}

The study combined qualitative and quantitative methods. The qualitative stage aimed at gaining in-depth insights into the topic and included 20 short interviews, ten in-depth interviews, and two focus groups. During this phase, scales from the literature were translated into Portuguese and discussed with participants, to assess the equivalence in meaning and salience of the constructs (Douglas \& Nijssen, 2003). A questionnaire was, then, designed and pre-tested using face-to-face and online procedures, involving 109 respondents. Comments were considered in the final version of the questionnaire. A back translation was performed to ensure the quality and accuracy of measures.

In the quantitative stage, the resulting questionnaire was implemented through an online survey. This method was considered appropriate to collect data, since online purchase behaviour is the object of study. An invitation with a hyperlink to the survey was sent using 
a database with 20,000 email addresses. After three follow-ups using email and personal contacts, 705 responses were received, 524 of which were considered valid. The sample size secured an acceptable margin of error of .04, for an alpha of .05 and an estimated variance of .50 (Cochran, 1977).

\subsection{Sample profile}

Concerning the respondent's profile, $62.8 \%$ are female, and $37.2 \%$ are male. Nearly $57 \%$ are aged between 16 and 24 years old, while $40 \%$ are aged between 25 and 54 years old. The higher proportion of respondents within the first group may reflect the fact that there is a higher internet usage and online shopping within this age range of the Portuguese population. According to OECD (2018) data, in 2016 54.4\% of the Portuguese population within the first age group were online shoppers while within the latter group the proportion of online shoppers was of $42.5 \%$. On average, $56.5 \%$ of the respondents made a purchase on the Internet less than five times during the previous year, and $58.5 \%$ made their first purchase on the Internet more than two years ago. Nearly $29 \%$ of the respondents spent more than $€ 190$ (approximately \$228).

\subsection{Measurement scales}

Items from existing validated scales were adapted. Respondents assessed each item using a seven-point Likert scale. Perceived risks of the Internet were measured using four items from Kim et al. (2008)'s scale, capturing privacy, security, financial and product risks. This construct was treated as formative. Trust in the Internet was operationalised through three items from Jarvenpaa, Tractinsky, and Vitale (2000)'s scale of store trustworthiness, and the construct was treated as reflective. Perceived benefits of Internet use were measured from a utilitarian standpoint, using four items from Kim et al. (2008)'s scale, and the construct was treated as formative. Intention to purchase online was captured using three items from Kim et al. (2008)'s, and the construct was treated as reflective.

The frequency of purchase was measured using an ordinal scale, ranging from $1=$ Never to $7=$ More than 17 times. The amount of money spent was also measured with an ordinal scale ranging from $1=$ Less than 10 Euros to $8=$ More than 190 Euros. Finally, to capture the level of trust with online payment methods, seven of the most used payment methods in Portugal, according to SIBS (2017) ${ }^{1}$ were selected: PayPal, PaySafe Card, MBNet, Bank Transfer, Debit Card, Credit Card, and Cash on Delivery. Traditional offline post-payment on delivery was also included. Such payment methods can be catalogued in the four widely used online payment methods: electronic-cash; pre-paid card; credit card and debit card (Kim et al., 2010). Payment methods were rated using a seven-point scale ranging from totally untrustworthy to totally trustworthy.

\footnotetext{
1 SIBS (Sociedade Interbancária de Serviços - Interbank Service Company) is a company responsible for processing transactions across the multiple payment systems.
} 


\section{Research findings and discussion}

Data were analysed using the Partial Least Squares (PLS) with SmartPLS 3.2.4 (Ringle, Wende, \& Becker, 2015). PLS makes minimal demands on sample size and residual distributions to achieve sufficient statistical power (Sarstedt \& Ringle, 2010) and, most importantly, enables the use of formative and reflective indicators, which is particularly useful in the present study. Data analysis follows a two-step approach, as recommended by Anderson and Gerbing (1988). The first step involves the assessment of reliability and validity of the measurement model, while the second step tests the structural relationships between the latent constructs. Reflective and formative constructs require different statistical treatment. Concerning the reflective items, the adequacy of the measurement model must be evaluated for reliability, convergent validity, and discriminant validity, whereas for formative items, the multicollinearity among items and its correspondent weights were assessed.

\subsection{Reliability and construct validity}

First, to assess the measurement model, particularly of the reflective constructs, the internal consistency for reliability was estimated using Cronbach's Alpha, rho_A and Composite Reliability (Fornell \& Larcker, 1981; Hair Jr, Hult, Ringle, \& Sarstedt, 2016a; Latan \& Noonan, 2017). Results confirmed that all reliability values exceed the cut-off point level of 0.70 (Table 1), evidencing a good level of internal consistency (Nunnally \& Bernstein, 1994). Additionally, construct validity was estimated by evaluating convergent and discriminant validity. Convergent validity was assessed by two criteria: 1 ) all indicator/item loadings need to be significant and exceed 0.70; and 2) the average variance extracted (AVE) for all reflective constructs should be higher than 0.50 (Bagozzi \& Youjae, 1988). As shown in Table 1, all reflective items exhibit loading factors higher than 0.70 on their particular construct and all the AVEs range from 0.72 to 0.78 , thus confirming both conditions for convergent validity. Second, as previously mentioned, two formative constructs were used (perceived risk and perceived benefits), so the potential multicollinearity among items was first analysed and their weights were tested. The maximum variance inflation factor (VIF) values for the manifest variables that shape both formative constructs vary between 1.05 to 1.85 , which means that most values are within the acceptable threshold of 3.3 (Hair Jr et al., 2016a) (see Table 1).

Discriminant validity was assessed with Fornell and Larcker (1981)'s criterion. However, it has received recent criticism for not detecting the absence of discriminant validity in common research surveys (Henseler, Ringle, \& Sarstedt, 2015). The alternative heterotraitmonotrait ratio of correlations criterion (HTMT) proposed by Henseler et al. (2015) was also used. Concerning the first criterion, the square root of AVE (i.e. the diagonal in Table 2) should be higher than the level of correlations (i.e., the off-diagonal elements) involving the construct (Fornell \& Larcker, 1981). This applies only to reflective items. The study confirms both criteria (Table 2). For the second criterion, the highest value obtained was 0.71 , which is lower than the threshold of $0.85\left(\mathrm{HTMT}_{0.85}\right)$ (Kline, 2011) and $0.90\left(\mathrm{HTMT}_{0.90}\right)$ (Gold, Malhotra, \& Segars, 2001), indicating that there is no concern about discriminant validity. Thus, most constructs showed appropriate measurement properties. 
Table 1. Measurement model (Reflective and Formative constructs)

\begin{tabular}{|c|c|c|c|c|}
\hline Construct / Items & VIF & Weight & Loadings & $\mathrm{t}$ - value \\
\hline \multicolumn{5}{|l|}{ Perceived risk - F } \\
\hline $\begin{array}{l}\text { Buying on the Internet is less secure than buying } \\
\text { offline }\end{array}$ & 1.05 & $-0.43^{* *}$ & & \\
\hline $\begin{array}{l}\text { The risk of purchased products on the Internet not } \\
\text { working properly is greater }\end{array}$ & 1.38 & $-0.26^{*}$ & & \\
\hline $\begin{array}{l}\text { Buying on the Internet is usually associated with a } \\
\text { significant risk of fraud compared to offline shop- } \\
\text { ping }\end{array}$ & 1.41 & $-0.14^{*}$ & & \\
\hline $\begin{array}{l}\text { I believe that online firms do not take all precau- } \\
\text { tions to protect personal and banking data from } \\
\text { their clients }\end{array}$ & 1.05 & $0.80^{* * *}$ & & \\
\hline \multicolumn{5}{|l|}{ Perceived Benefits of Internet use - F } \\
\hline $\begin{array}{l}\text { I can save money (prices are lower) by purchasing } \\
\text { on the Internet }\end{array}$ & 1.46 & $0.35^{* * *}$ & & 8.2 \\
\hline $\begin{array}{l}\text { Purchasing on the Internet increases my produc- } \\
\text { tivity }\end{array}$ & 1.85 & $0.32^{* * *}$ & & 6.2 \\
\hline Purchasing on the Internet is more convenient & 1.83 & $0.51^{* * *}$ & & 10.2 \\
\hline \multicolumn{5}{|l|}{$\begin{array}{l}\text { Trust on the Internet }-R \\
{[\mathrm{CR}=0.88 ; \text { rho_A }=0.84 ; \mathrm{CA}=0.80 ; \mathrm{AVE}=0.72]}\end{array}$} \\
\hline $\begin{array}{l}\text { I believe that firms that sell their products on the } \\
\text { Internet are concerned with the interests of their } \\
\text { clients. }\end{array}$ & & & $0.89^{* * *}$ & 76.9 \\
\hline $\begin{array}{l}\text { I believe that firms that sell their products on the } \\
\text { Internet keep their promises to their clients }\end{array}$ & & & $0.91^{* * *}$ & 88.2 \\
\hline $\begin{array}{l}\text { I believe that firms that sell their products on the } \\
\text { Internet have more to lose if they do not accom- } \\
\text { plish their promises }\end{array}$ & & & $0.74^{* * *}$ & 24.0 \\
\hline \multicolumn{5}{|l|}{$\begin{array}{l}\text { Intention to purchase on the Internet }-R \\
{[\mathrm{CR}=0.91 ; \text { rho_A }=0.86 ; \mathrm{CA}=0.86 ; \mathrm{AVE}=0.78]}\end{array}$} \\
\hline $\begin{array}{l}\text { The idea to purchase on the Internet is very attrac- } \\
\text { tive to me }\end{array}$ & & & $0.89^{* * *}$ & 76.1 \\
\hline I love to purchase products on the Internet & & & $0.91^{\star * *}$ & 123.0 \\
\hline $\begin{array}{l}\text { I am likely to make another purchase on the Inter- } \\
\text { net in the future }\end{array}$ & & & $0.85^{\star \star \star}$ & 48.2 \\
\hline
\end{tabular}

Note: ${ }^{\star} \mathrm{p}<0.05 ;{ }^{* *} \mathrm{p}<0.01 ;{ }^{* * \star} \mathrm{p}<0.001 ; \mathrm{F}$ (Formative); R (Reflective); VIF (Variance Inflation Factor);

CR (Composite Reliability); CA (Cronbach Alpha); AVE (Average Variance Extracted). 
Table 2. Pearson Correlations, Means and Standard Deviations

\begin{tabular}{|l|c|c|c|c|c|c|c|c|c|c|}
\hline Fornell-Larcker & 1 & 2 & 3 & 4 & 5 & 6 & HTMT & 1 & 3 & 5 \\
\hline Intention & $(0.88)$ & & & & & & $(1)$ & & & \\
\hline Perc_Benefits (F) & 0.77 & (n.a) & & & & & $(2)$ & & & \\
\hline $\begin{array}{l}\text { Frequency } \\
\text { purchase }\end{array}$ & 0.51 & 0.44 & (n.a) & & & & $(3)$ & 0.55 & & \\
\hline Perceived Risk (F) & -0.42 & -0.41 & -0.25 & (n.a) & & & $(4)$ & & & \\
\hline Trust & 0.61 & 0.65 & 0.33 & -0.45 & $(0.85)$ & & $(5)$ & 0.71 & 0.37 & \\
\hline Amount Purchase & 0.36 & 0.27 & 0.50 & -0.29 & 0.25 & & $(6)$ & 0.39 & 0.50 & 0.27 \\
\hline Mean & 4.77 & 4.64 & 3.32 & 3.95 & 4.48 & 4.57 & & & & \\
\hline $\begin{array}{l}\text { Standard } \\
\text { Deviation }\end{array}$ & 1.46 & 1.28 & 1.68 & 0.70 & 1.21 & 2.06 & & & & \\
\hline
\end{tabular}

Note: The diagonal (in brackets) shows the square roots of the AVE; One-tailed.

\subsection{Structural model}

The bootstrapping technique was used to test the coefficients' significance (5,000 valid subsamples were extracted). According to Chin (1998), goodness-of-fit in a PLS estimation is demonstrated by strong factor loadings (or correlations), significant path coefficients, and high $\mathrm{R}^{2}$ values. One feature of PLS path modelling lies in maximising the variance explained for all endogenous variables in the model, which means that PLS is a suitable tool for situations in which the researcher wants to identify and predict relationships between constructs. Finally, the standardised root mean square residual (SRMR), was computed. This measure of fit assumes a 0.08 cut-off point (Hu \& Bentler, 1999). The data reveal that the model shows a good fit $(\mathrm{SRMR}=0.06)$.

The predictive power of the model was examined using $\mathrm{R}^{2}$. Through the PLS algorithm function, $\mathrm{R}^{2}$ was computed to five endogenous constructs, namely 0.62 for intention to purchase on the Internet, 0.42 for perceived benefits of Internet use, 0.20 for trust in the Internet, 0.26 for frequency of purchase and 0.13 for amount of purchase. The Goodness of Fit (GoF) index and the Stone-Geisser cross-validation tests were computed in order to obtain a global fit measure beyond $\mathrm{R}^{2}$. The Stone-Geisser tests results for reflective constructs indicate that the model shows good predictive validity $\left(\mathrm{Q}^{2}>0\right)$ (Table 3 ).

Table 3. Effect size of the endogenous variables

\begin{tabular}{|l|c|c|c|}
\hline \multicolumn{1}{|c|}{ Latent Variables } & $\mathrm{R}^{2}$ & CV-C Q & CV-R Q $^{2}$ \\
\hline Intention to Purchase & 0.62 & 0.78 & 0.46 \\
\hline Perceived Benefits & 0.42 & 0.69 & 0.29 \\
\hline Trust & 0.20 & 0.72 & 0.14 \\
\hline Frequency of Purchase & 0.26 & 1.00 & 0.26 \\
\hline Amount of Purchase & 0.13 & 1.00 & 0.13 \\
\hline
\end{tabular}

Note: CV-C (Cross-validated communality); CV-R (Cross-validated redundancy). 
The six proposed hypotheses are confirmed (Table 4). Specifically, Hypothesis 1 ( $\beta=$ $-0.45)$ predicted that the perceived risk has a negative impact on trust. This is followed by Hypothesis $2(\beta=0.18)$, which predicted that trust in the Internet has a positive impact on the intention to purchase on the Internet. Hypothesis $3(\beta=0.65)$, which indicated that trust in the Internet has a positive impact on the perceived benefits of Internet use, was supported as well. The same result was found for Hypothesis $4(\beta=0.66)$, which predicted that the perceived benefits of Internet use have a positive impact on the intention to purchase on the Internet. Finally, the study also confirms the two consequences of intention to purchase on the Internet: the study supports Hypothesis $5(\beta=0.36)$, which predicted that the intention to purchase on the Internet has a positive impact on the amount of purchase (AoP) and Hypothesis $6(\beta=0.51)$, which stated that intention to purchase on the Internet has a positive impact on the frequency of purchase (FoP). Succinctly, the study validates all antecedents and consequences of intention to purchase on the Internet.

Research on the antecedents of online purchase intention, considered trust as an antecedent of perceived risk, which influences intentions (Agag \& El-Masry, 2017; Kim et al., 2008). These results strengthen previous research, contributing for the growing knowledge on the antecedents of online trust and its consequences. Trust was also found to affect the perceived benefits of the online channel positively. Although some research has provided evidence that trust in the Internet leads to more positive attitudes towards online shopping (Al-Debei et al., 2015), this study focused particularly on perceived benefits, which has often been considered an antecedent of trust (Bilgihan, 2016; Yang et al., 2015). Finally, the study confirmed the relationship between online purchase intention and actual purchase behaviour. The bootstrapping procedure (with 5,000 samples), which does not impose any assumption of normality on the sampling distribution, was used to generate t-statistics, confidence intervals and standard errors (Table 4).

Table 4. Effects on endogenous variables (direct effects)

\begin{tabular}{|l|c|c|c|c|c|c|l|}
\hline \multicolumn{1}{|c|}{ Relationships } & $\begin{array}{c}\text { Sug- } \\
\text { gested } \\
\text { effect }\end{array}$ & $\begin{array}{c}\text { Direct } \\
\text { Effect }(\beta)\end{array}$ & $\begin{array}{c}\text { t-value } \\
\text { boot- } \\
\text { strap) }\end{array}$ & $\begin{array}{c}\text { Percentile } \\
95 \% \text { confi- } \\
\text { dence } \\
\text { intervals }\end{array}$ & $\begin{array}{c}\text { Stan- } \\
\text { dard } \\
\text { errors }\end{array}$ & $\begin{array}{c}\text { Ex- } \\
\text { plained } \\
\text { Vari- } \\
\text { ance }\end{array}$ & Decision \\
\hline H1: $\mathrm{PR} \rightarrow \mathrm{T}$ & $(-)$ & $-0.45^{* *}$ & 2.34 & {$[0.391-0.519]$} & 0.039 & $18 \%$ & Supported \\
\hline H2: $\mathrm{T} \rightarrow \mathrm{Int}$ & $(+)$ & $0.18^{* * *}$ & 4.19 & {$[0.109-0.246]$} & 0.042 & $10 \%$ & Supported \\
\hline H3: $\mathrm{T} \rightarrow \mathrm{PB}$ & $(+)$ & $0.65^{* * *}$ & 21.10 & {$[0.595-0.699]$} & 0.031 & $42 \%$ & Supported \\
\hline H4: $\mathrm{PB} \rightarrow \mathrm{Int}$ & $(+)$ & $0.66^{* *}$ & 17.20 & {$[0.593-0.718]$} & 0.038 & $50 \%$ & Supported \\
\hline H5: $\mathrm{Int} \rightarrow \mathrm{AoP}$ & $(+)$ & $0.36^{* * *}$ & 9.63 & {$[0.299-0.423]$} & 0.037 & $12 \%$ & Supported \\
\hline H6: $\mathrm{Int} \rightarrow \mathrm{FoP}$ & $(+)$ & $0.51^{* * *}$ & 15.80 & {$[0.454-0.563]$} & 0.033 & $26 \%$ & Supported \\
\hline
\end{tabular}

Note: $\mathrm{PR}=$ Perceived Risk; $\mathrm{T}=$ Trust Int = Intention; $\mathrm{PB}=$ Perceived Benefit; AoP = Amount of Purchase; FoP $=$ Frequency of Purchase; Based on $t(4999) ;{ }^{*} p<0.05 ; t(0.05 ; 4999)=1.645 ;{ }^{* *} p<0.01$; $\mathrm{t}(0.01 ; 4999)=2.327 ;{ }^{* *} p<0.001 ; \mathrm{t}(0.001 ; 4999)=3.092 ; \dagger$ bias-corrected and accelerated (BCa) BCI; one-tailed. ${ }^{\star} p<0.05 ;{ }^{* *} p<0.01 ;{ }^{* *} p<0.001$. 


\subsection{FIMIX analysis for sample heterogeneity}

Sample homogeneity is often unrealistic, so the present study employed the FIMIX-PLS approach to account for heterogeneity in the research sample (Ringle, Sarstedt, \& Mooi, 2010). The following procedures were used: 1 ) a stop criterion of $1.0 \mathrm{E}-10$ and a maximum number of 5,000 iterations; 2) 10 repetitions to avoid convergence in a local optimum; 3) definition of a reasonable segment number; and 4) avoidance in using the mean value replacement (Hair Jr et al., 2016b). To evaluate results, the information criteria consistent AIC (CAIC) and the normed entropy criterion (EN) were considered jointly to determine the number of data segments that should be retained (Sarstedt, Becker, Ringle, \& Schwaiger, 2011). While the lowest value of CAIC indicates the optimal segment solution, the EN shows how well the segments are distinguishable (Sarstedt et al., 2011). The EN can reach values between 0 and 1 and should at least reach a value of 0.5 (Sarstedt et al., 2011)

A comparison of goodness-of-fit indices obtained from the FIMIX-PLS procedure suggested that the choices of two segments were the most appropriate (Table 5). Segment 1 comprises $69.5 \%\left(n_{1}=364\right)$ and segment 2 includes $30.5 \%\left(n_{2}=159\right)$ of the corresponding segment.

Table 5. FIMIX-PLS evaluation criteria

\begin{tabular}{|l|c|c|}
\hline \multicolumn{1}{|c|}{ Number of segments } & CAIC & EN \\
\hline Segment 1 & $6.277,46$ & 0.59 \\
\hline Segment 2 & $6.310,94$ & 0.52 \\
\hline
\end{tabular}

The next step involved finding an explanatory variable that could clarify potential differences between segments 1 and 2. Due to its importance for online purchase, it was decided to explore whether the level of trust associated to different electronic payment methods, the level of experience of Internet use and the gender cause any potential source of heterogeneity. The former two variables were dichotomised into low-level of trust (Credit Card, Debit Card and Bank Transfer) and high-level of trust (Payment Safe Card, PayPal, MBNet, and Payment on Collection) (Table 6), and high and low experience in using the Internet. Subsequently, a multiple group analysis was performed considering each variable as a moderator.

Table 6. Trust in the payment methods

\begin{tabular}{|l|c|c|}
\hline & Mean & Std. Dev. \\
\hline Safecard & 6.25 & 1.406 \\
\hline PayPal & 5.60 & 1.465 \\
\hline MBnet & 5.52 & 1.426 \\
\hline Payment on Collection & 5.50 & 1.374 \\
\hline Debit Card & 5.03 & 1.790 \\
\hline Bank Transfer & 4.84 & 1.442 \\
\hline Credit Card & 4.61 & 1.750 \\
\hline
\end{tabular}

Note: Responses vary from a minimum of 1 (totally untrustworthy) to a maximum of 7 (totally trust- worthy); $N=524$. 
As Table 7 illustrates, some heterogeneity was observed in the sample regarding the level of trust in electronic payments and experience: higher and lower trust in electronic systems impacts significantly and differently on the relationship between the online purchase intention and the amount of purchase (INT $\rightarrow$ AoP), as well as on the relationship between the online purchase intention and frequency of purchase (INT $\rightarrow$ FoP). Specifically, when using electronic systems of payment deemed to have a higher level of trust, the impact of intention to purchase on the Internet on the frequency and amount of purchase is higher than when using systems deemed less trustworthy. This result confirms the relevance of trust (Kim et al., 2010; Yang et al., 2015) and highlights the role of the availability of reliable payment methods to narrowing the online purchase intention-behaviour gap.

Table 7. Results of Heterogeneity analysis

\begin{tabular}{|c|c|c|c|c|c|c|c|c|c|c|c|c|}
\hline \multicolumn{13}{|c|}{ Security - Low Level Trust - High level Trust } \\
\hline & $\mathrm{N}$ & $\beta$ & $\mathrm{T}$ & p. & $\mathrm{Se}$ & $\mathrm{N}$ & $\beta$ & $\mathrm{T}$ & p. & $\mathrm{Se}$ & $\mathrm{t}$ & p. \\
\hline $\mathrm{PR} \rightarrow \mathrm{T}$ & 206 & -0.30 & 1.46 & 0.14 & 0.26 & 318 & -0.39 & 1.54 & 0.12 & 0.32 & 0.26 & 0.79 \\
\hline $\mathrm{T} \rightarrow$ Int & 206 & 0.16 & 2.99 & 0.00 & 0.05 & 318 & 0.18 & 3.31 & 0.00 & 0.05 & 0.12 & 0.89 \\
\hline $\mathrm{T} \rightarrow \mathrm{PB}$ & 206 & 0.65 & 13.70 & 0.00 & 0.04 & 318 & 0.66 & 16.32 & 0.00 & 0.04 & 0.28 & 0.77 \\
\hline $\mathrm{PB} \rightarrow \mathrm{Int}$ & 206 & 0.66 & 13.71 & 0.00 & 0.04 & 318 & 0.65 & 12.68 & 0.00 & 0.05 & 0.11 & 0.90 \\
\hline Int $\rightarrow$ AoP & 206 & 0.19 & 2.87 & 0.00 & 0.06 & 318 & 0.45 & 11.12 & 0.00 & 0.04 & 3.58 & $0.00^{\star * *}$ \\
\hline Int $\rightarrow$ FoP & 206 & 0.40 & 7.48 & 0.00 & 0.05 & 318 & 0.57 & 14.21 & 0.00 & 0.04 & 2.60 & $0.01^{\star \star}$ \\
\hline \multicolumn{13}{|c|}{ Experience - Low Experience - High Experience } \\
\hline $\mathrm{PR} \rightarrow \mathrm{T}$ & 55 & 0.65 & 4.89 & 0.00 & 0.13 & 469 & -0.43 & 4.89 & 0.00 & 0.08 & 4.91 & $0.00^{* * *}$ \\
\hline $\mathrm{T} \rightarrow$ Int & 55 & 0.02 & 0.24 & 0.80 & 0.11 & 469 & 0.18 & 4.20 & 0.00 & 0.04 & 1.17 & 0.24 \\
\hline $\mathrm{T} \rightarrow \mathrm{PB}$ & 55 & 0.67 & 6.99 & 0.00 & 0.09 & 469 & 0.64 & 19.22 & 0.00 & 0.03 & 0.22 & 0.82 \\
\hline $\mathrm{PB} \rightarrow$ Int & 55 & 0.80 & 9.13 & 0.00 & 0.08 & 469 & 0.63 & 15.99 & 0.00 & 0.04 & 1.41 & 0.15 \\
\hline Int $\rightarrow$ AoP & 55 & 0.37 & 4.07 & 0.00 & 0.09 & 469 & 0.33 & 8.00 & 0.00 & 0.04 & 0.28 & 0.77 \\
\hline Int $\rightarrow$ FoP & 55 & 0.56 & 6.33 & 0.00 & 0.08 & 469 & 0.48 & 13.13 & 0.00 & 0.03 & 0.68 & 0.49 \\
\hline \multicolumn{13}{|c|}{ Gender - Male - Female } \\
\hline $\mathrm{PR} \rightarrow \mathrm{T}$ & 168 & -0.31 & 1.41 & 0.15 & 0.27 & 285 & -0.37 & 1.40 & 0.16 & 0.36 & 0.22 & 0.82 \\
\hline $\mathrm{T} \rightarrow$ Int & 168 & 0.08 & 1.34 & 0.17 & 0.07 & 285 & 0.21 & 3.99 & 0.00 & 0.05 & 1.42 & 0.15 \\
\hline $\mathrm{T} \rightarrow \mathrm{PB}$ & 168 & 0.61 & 12.10 & 0.00 & 0.05 & 285 & 0.65 & 14.80 & 0.00 & 0.04 & 0.60 & 0.54 \\
\hline $\mathrm{PB} \rightarrow$ Int & 168 & 0.67 & 9.55 & 0.00 & 0.07 & 285 & 0.64 & 12.70 & 0.00 & 0.05 & 0.35 & 0.72 \\
\hline Int $\rightarrow$ AoP & 168 & 0.40 & 6.10 & 0.00 & 0.06 & 285 & 0.31 & 6.34 & 0.00 & 0.05 & 1.09 & 0.27 \\
\hline $\mathrm{Int} \rightarrow \mathrm{FoP}$ & 168 & 0.46 & 6.69 & 0.00 & 0.06 & 285 & 0.56 & 14.40 & 0.00 & 0.03 & 1.35 & 0.17 \\
\hline
\end{tabular}

Note: $\mathrm{PR}=$ Perceived Risk; $\mathrm{T}=$ Trust; Int = Intention; $\mathrm{PB}=$ Perceived Benefit; AoP = Amount of Purchase; FoP = Frequency of Purchase; ${ }^{*} \mathrm{p}<0.05 ;{ }^{* *} \mathrm{p}<0.01 ;{ }^{* * *} \mathrm{p}<0.001$.

Low and high experience with Internet use has a significant impact on the direction of the relationship between perceived risk and trust $(\mathrm{PR} \rightarrow \mathrm{T})$. For high experienced users, perceived risk impacts negatively on trust, while for low experienced users, the effect is positive. These results are consistent with Constantinides, Lorenzo-Romero, and Gómez (2010). While high 
experienced consumers' perceived risk influences negatively on trust in the Internet, this result is positive for the group of low experienced consumers. This result may be explained by the fact that experienced online consumers engage more in security behaviours (Jeske \& van Schaik, 2017), which lower their perception of risk and contribute to increasing their trust in the medium. Familiarity was, in fact, previously associated with higher trust (Sharma et al., 2017) and perceived security (Ponte et al., 2015). The less experienced consumers may lack skills to assess the internet risks correctly. So, if their perceptions of risk are high, due to the uncertainty involved, they need to rely on their trust to perform the behaviour. This would be consistent with research that shows that, when confronted with a situation involving risk, such as sharing sensitive information with a non-familiar website, internet users tend to rely on their gut feeling, rather than on a deliberative decision process (Roghanizad \& Neufeld, 2015). With repetition and a better understanding of the medium and the process, an increase in the predictive negative effect of perceived risk in the decision to trust in the online vendor is expected (Hong \& Cha, 2013). The results suggest that the influence of online consumers' experience or familiarity with the Internet and online shopping is important and should be further explored, contributing to the understanding of the role of trust for the online purchase behaviour.

Noticeably, gender does not interact significantly in the proposed relationships. Some literature found that, compared to women, men tend to be described as more task-oriented, pragmatic, enticed by hedonic benefits and risk-takers, being more confident and prone to adopt the Internet and to shop online (Van Slyke, Bélanger, Johnson, \& Hightower, 2010; Zhou, Jin, \& Fang, 2014). However, the results of this study support a trend towards dissipating differences between genders in online purchase behaviour in a context of a growing Internet and e-commerce adoption (Chen et al., 2015; Fang et al., 2016).

\section{Conclusions}

The purpose of this article was to assess the antecedents of online shopping intention and online shopping behaviour, to clarify the effect of trust on the perceived benefits, while exploring the importance of the perceived risk as a predictor of trust in the online channel. It also pretended to identify sources of heterogeneity within different relationships. For this purpose, a model capturing the relationships of perceived risk, trust in the Internet, online perceived benefits, online purchase intention and actual purchase was developed, tested and supported.

This study approached the critical variable of trust as a consequence of perceived risk, confirming that trust in the online environment is negatively affected by higher perceptions of risk, which also affects online purchase intention and behaviour. The results also support that trust affects positively the perceived benefits of the online channel. Finally, the relationship between online purchase intention and actual purchase behaviour was also confirmed.

The FIMIX-PLS provided some evidence of heterogeneity in the causal relationships proposed. This methodology offers an important contribution, inasmuch that it allows to identify groups of consumers that display differences in their online purchase behaviour. In particular, results show that the level of trust in different payment methods may be relevant 
to understand the impact of online purchase intention on the actual purchase. The study indicates that the effects of online purchase intention on both the amount of purchase (AoP) and on the frequency of purchase (FoP) are stronger when the consumer uses payment methods with a higher level of trust. This result suggests that the availability of more reliable payment methods may contribute to converting purchase intentions into actual purchases. This result confirms the relevance of trust and highlights the role of the availability of reliable payment methods to narrowing the online purchase intention-behaviour gap.

Another significant result relates to the influence of the level of consumer experience with the Internet. High experienced users and low experienced users exhibit differences regarding the relationship between their perceptions of risk and trust in the Internet. These results suggest that the influence of online consumers' experience or familiarity with the Internet and online shopping is important and should be further explored, contributing to the understanding of the role of trust for the online purchase behaviour.

The study is not exempt from limitations, though. Firstly, caution needs to be taken in generalising research findings to a broader population. Although online shopping is the object of study, online surveys present some potential biases, as self-selection, non-response bias and low response rates. Secondly, all constructs were measured through self-reported perceptions, sharing customers' constructions about their realities. Perceptions and reality are not synonymous, so differences between what is said, what is felt, and what is done may occur.

From a theoretical perspective, this research makes an additional contribution to clarifying the intriguing relationship between perceived risk and trust, demonstrating that the first predicts the latter. The use of FIMIX-PLS represents a step forward in the analysis, suggesting its use to uncover relevant relationships and deepen the understanding of data. From a managerial perspective, results provide useful recommendations for e-commerce managers, regarding segmentation, product decisions, and website design and communication. Results confirmed the relevance of trust in the Internet for raising purchase intentions and actual purchase, and for improving perceived benefits. Therefore, managers should focus on building such trust, namely using guarantees to lower the perception of risk. Additionally, providing higher trust payment methods may be an effective way to make consumers move from intention to action.

Future research should address the complexity of variables that may explain customer's intentions to purchase online. To improve the comprehension of the modelled relationships, it is essential to use mix methodologies and methods that integrate the customer's communicated sense-making and big data that effectively track online purchasing activities, beyond the self-reported behaviour. Big data are also essential to test multiple scenarios related to the vendor's value proposition, augmenting the complexity of the analysis. Finally, FIMIX-PLS data analysis has potential to explore various sources of heterogeneity and may be replicated in future studies. Such avenues of research should provide a better understanding of the stimulus-response nature and process.

\section{References}

Agag, G. M., \& El-Masry, A. A. (2017). Why do consumers trust online travel websites? Drivers and outcomes of consumer trust toward online travel websites. Journal of Travel Research, 56(3), 347369. https://doi.org/10.1177/0047287516643185 
Al-Debei, M. M., Akroush, M. N., \& Ashouri, M. I. (2015). Consumer attitudes towards online shopping. Internet Research, 25(5), 707-733. https://doi.org/10.1108/IntR-05-2014-0146

Anderson, J. C., \& Gerbing, D. W. (1988). Structural equation modeling in practice: a review and recommended two-step approach. Psychological Bulletin, 103(3), 411-423. https://doi.org/10.1037/0033-2909.103.3.411

Arce-Urriza, M., Cebollada, J., \& Tarira, M. F. (2017). The effect of price promotions on consumer shopping behavior across online and offline channels: differences between frequent and non-frequent shoppers. Information Systems and e-Business Management, 15(1), 69-87. https://doi.org/10.1007/s10257-016-0310-2

Bagozzi, R. P., \& Youjae, Y. (1988). On the evaluation of structural equation models. Journal of the Academy of Marketing Science, 16(1), 74-94. https://doi.org/10.1177/009207038801600107

Bilgihan, A. (2016). Gen Y customer loyalty in online shopping: an integrated model of trust, user experience and branding. Computers in Human Behavior, 61, 103-113. https://doi.org/10.1016/j.chb.2016.03.014

Büttner, O. B., \& Göritz, A. S. (2008). Perceived trustworthiness of online shops. Journal of Consumer Behaviour, 7(1), 35-50. https://doi.org/10.1002/cb.235

Chang, H. H., \& Chen, S. W. (2008). The impact of online store environment cues on purchase intention. Online Information Review, 32(6), 818-841. https://doi.org/10.1108/14684520810923953

Chang, M. K., Cheung, W., \& Lai, V. S. (2005). Literature derived reference models for the adoption of online shopping. Information \& Management, 42(4), 543-559. https://doi.org/10.1016/j.im.2004.02.006

Chen, Y., Yan, X., Fan, W., \& Gordon, M. (2015). The joint moderating role of trust propensity and gender on consumers' online shopping behavior. Computers in Human Behavior, 43, 272-283. https://doi.org/10.1016/j.chb.2014.10.020

Chien, S.-H., Chen, Y.-H., \& Hsu, C.-Y. (2012). Exploring the impact of trust and relational embeddedness in e-marketplaces: an empirical study in Taiwan. Industrial Marketing Management, 41(3), 460-468. https://doi.org/10.1016/j.indmarman.2011.05.001

Childers, T. L., Carr, C. L., Peck, J., \& Carson, S. (2001). Hedonic and utilitarian motivations for online retail shopping behavior. Journal of Retailing, 77(4), 511-535. https://doi.org/10.1016/S0022-4359(01)00056-2

Chin, W. W. (1998). The partial least squares approach for structural equation modeling. In G. A. Marcoulides (Ed.), Modern methods for business research (pp. 295-336). New York, NY: Psychology Press.

Clemons, E. K., Wilson, J., Matt, C., Hess, T., Ren, F., Jin, F., \& Koh, N. S. (2016). Global differences in online shopping behavior: understanding factors leading to trust. Journal of Management Information Systems, 33(4), 1117-1148. https://doi.org/10.1080/07421222.2016.1267531

Cochran, W. G. (1977). Sampling techniques (3rd ed.). New York: John Wiley \& Sons.

Comegys, C., Hannula, M., \& Váisánen, J. (2009). Effects of consumer trust and risk on online purchase decision-making: a comparison of Finnish and United States students. International Journal of Management, 26(2), 295.

Constantinides, E., LorenzoRomero, C., \& Gómez, M. A. (2010). Effects of web experience on consumer choice: a multicultural approach. Internet Research, 20(2), 188-209. https://doi.org/10.1108/10662241011032245

Corritore, C. L., Kracher, B., \& Wiedenbeck, S. (2003). On-line trust: concepts, evolving themes, a model. International Journal of Human-Computer Studies, 58(6), 737-758. https://doi.org/10.1016/S1071-5819(03)00041-7

Díaz, A., Gómez, M., \& Molina, A. (2017). A comparison of online and offline consumer behaviour: an empirical study on a cinema shopping context. Journal of Retailing and Consumer Services, 38, 44-50. https://doi.org/10.1016/j.jretconser.2017.05.003 
Dodds, W. B., \& Monroe, K. B. (1985). The effect of brand and price information on subjective product evaluations. In E. C. H. \& M. B. Holbrook (Eds.), NA - Advances in Consumer Research (pp. 85-90). Provo, UT: Association for Consumer Research.

Douglas, S. P., \& Nijssen, E. J. (2003). On the use of "borrowed" scales in cross-national research: a cautionary note. International Marketing Review, 20(6), 621-642.

https://doi.org/10.1108/02651330310505222

Escobar-Rodríguez, T., \& Bonsón-Fernández, R. (2017). Analysing online purchase intention in Spain: fashion e-commerce. Information Systems and e-Business Management, 15(3), 599-622. https://doi.org/10.1007/s10257-016-0319-6

Fang, J., Wen, C., George, B., \& Prybutok, V. R. (2016). Consumer heterogeneity, perceived value, and repurchase decision-making in online shopping: the role of gender, age, and shopping motives. Journal of Electronic Commerce Research, 17(2), 116-131.

Fornell, C., \& Larcker, D. F. (1981). Structural equation models with unobservable variables and measurement error: algebra and statistics. Journal of Marketing Research, 18(3), 382-388. https://doi.org/10.2307/3150980

Forsythe, S., Liu, C., Shannon, D., \& Gardner, L. C. (2006). Development of a scale to measure the perceived benefits and risks of online shopping. Journal of Interactive Marketing, 20(2), 55-75. https://doi.org/10.1002/dir.20061

Gold, A. H., Malhotra, A., \& Segars, A. H. (2001). Knowledge management: an organizational capabilities perspective. Journal of Management Information Systems, 18(1), 185-214. https://doi.org/10.1080/07421222.2001.11045669

Hair Jr, J. F., Hult, G. T. M., Ringle, C., \& Sarstedt, M. (2016a). A primer on partial least squares structural equation modeling (PLS-SEM). Thousand Oaks: Sage Publications.

Hair Jr., J. F., Sarstedt, M., Matthews, L. M., \& Ringle, C. M. (2016b). Identifying and treating unobserved heterogeneity with FIMIX-PLS: part I - method. European Business Review, 28(1), 63-76. https://doi.org/10.1108/EBR-09-2015-0094

Harridge-March, S. (2006). Can the building of trust overcome consumer perceived risk online. Marketing Intelligence \& Planning, 24(7), 746-761. https://doi.org/10.1108/02634500610711897

Henseler, J., Ringle, C. M., \& Sarstedt, M. (2015). A new criterion for assessing discriminant validity in variance-based structural equation modeling. Journal of the Academy of Marketing Science, 43(1), 115-135. https://doi.org/10.1007/s11747-014-0403-8

Hong, I. B. (2015). Understanding the consumer's online merchant selection process: the roles of product involvement, perceived risk, and trust expectation. International Journal of Information Management, 35(3), 322-336. https://doi.org/10.1016/j.ijinfomgt.2015.01.003

Hong, I. B., \& Cha, H. S. (2013). The mediating role of consumer trust in an online merchant in predicting purchase intention. International Journal of Information Management, 33(6), 927-939. https://doi.org/10.1016/j.ijinfomgt.2013.08.007

Hu, L., \& Bentler, P. M. (1999). Cutoff criteria for fit indexes in covariance structure analysis: conventional criteria versus new alternatives. Structural Equation Modeling: A Multidisciplinary Journal, 6(1), 1-55. https://doi.org/10.1080/10705519909540118

Hubert, M., Blut, M., Brock, C., Backhaus, C., \& Eberhardt, T. (2017). Acceptance of smartphonebased mobile shopping: mobile benefits, customer characteristics, perceived risks, and the impact of application context. Psychology \& Marketing, 34(2), 175-194. https://doi.org/10.1002/mar.20982

Jarvenpaa, S. L., Tractinsky, N., \& Vitale, M. (2000). Consumer trust in an Internet store. Information Technology and Management, 1(1/2), 45-71. https://doi.org/10.1023/A:1019104520776

Jasper, C. R., \& Ouellette, S. J. (1994). Consumers' perception of risk and the purchase of apparel from catalogs. Journal of Direct Marketing, 8(2), 23-36. https://doi.org/10.1002/dir.4000080205

Jeske, D., \& van Schaik, P. (2017). Familiarity with Internet threats: beyond awareness. Computers \& Security, 66, 129-141. https://doi.org/10.1016/j.cose.2017.01.010 
Kim, C., Tao, W., Shin, N., \& Kim, K.-S. (2010). An empirical study of customers' perceptions of security and trust in e-payment systems. Electronic Commerce Research and Applications, 9(1), 84-95. https://doi.org/10.1016/j.elerap.2009.04.014

Kim, D. J., Ferrin, D. L., \& Rao, H. R. (2008). A trust-based consumer decision-making model in electronic commerce: the role of trust, perceived risk, and their antecedents. Decision Support Systems, 44(2), 544-564. https://doi.org/10.1016/j.dss.2007.07.001

Kim, H.-W., Xu, Y., \& Gupta, S. (2012). Which is more important in Internet shopping, perceived price or trust. Electronic Commerce Research and Applications, 11(3), 241-252. https://doi.org/10.1016/j.elerap.2011.06.003

Kim, M.-J., Chung, N., \& Lee, C.-K. (2011). The effect of perceived trust on electronic commerce: shopping online for tourism products and services in South Korea. Tourism Management, 32(2), 256-265. https://doi.org/10.1016/j.tourman.2010.01.011

Kline, R. B. (2011). Principles and practice of structural equation modeling 2011 (3rd ed.). New York, NY: NY Guilford Press.

Latan, H., \& Noonan, R. (Eds.). (2017). Partial least squares path modeling: basic concepts, methodological issues and applications. Cham: Springer International Publishing. https://doi.org/10.1007/978-3-319-64069-3

Li, H., Kuo, C., \& Rusell, M. G. (2006). The impact of perceived channel utilities, shopping orientations, and demographics on the consumer's online buying behavior. Journal of Computer-Mediated Communication, 5(2), 0-0. https://doi.org/10.1111/j.1083-6101.1999.tb00336.x

Lin, H.-F. (2007). Predicting consumer intentions to shop online: an empirical test of competing theories. Electronic Commerce Research and Applications, 6(4), 433-442.

https://doi.org/10.1016/j.elerap.2007.02.002

Molinillo, S., Gómez-Ortiz, B., Pérez-Aranda, J., \& Navarro-García, A. (2017). Building customer loyalty: the effect of experiential state, the value of shopping, and trust and perceived value of service on online clothes shopping. Clothing and Textiles Research Journal, 35(3), 156-171. https://doi.org/10.1177/0887302X17694270

Mou, J., Shin, D.-H., \& Cohen, J. F. (2017). Trust and risk in consumer acceptance of e-services. Electronic Commerce Research, 17(2), 255-288. https://doi.org/10.1007/s10660-015-9205-4

Nepomuceno, M. V., Laroche, M., \& Richard, M.-O. (2014). How to reduce perceived risk when buying online: the interactions between intangibility, product knowledge, brand familiarity, privacy and security concerns. Journal of Retailing and Consumer Services, 21(4), 619-629. https://doi.org/10.1016/j.jretconser.2013.11.006

Nunnally, J. C., \& Bernstein, I. H. (1994). Psychometric theory. New York: McGraw-Hill.

OECD. (2018). ICT access and usage by individuals. Retrieved from https://stats.oecd.org

Pappas, N. (2017a). Effect of marketing activities, benefits, risks, confusion due to over-choice, price, quality and consumer trust on online tourism purchasing. Journal of Marketing Communications, 23(2), 195-218. https://doi.org/10.1080/13527266.2015.1061037

Pappas, N. (2017b). Risks and marketing in online transactions: a qualitative comparative analysis. Current Issues in Tourism, 20(8), 852-868. https://doi.org/10.1080/13683500.2016.1187586

Ponte, E. B., Carvajal-Trujillo, E., \& Escobar-Rodríguez, T. (2015). Influence of trust and perceived value on the intention to purchase travel online: integrating the effects of assurance on trust antecedents. Tourism Management, 47, 286-302. https://doi.org/10.1016/j.tourman.2014.10.009

Ringle, C. M., Wende, S., \& Becker, J.-M. (2015). SmartPLS3. Hamburg: SmartPLS. Retrieved from http//www.smartpls.com

Ringle, C. M., Sarstedt, M., \& Mooi, E. A. (2010). Response-based segmentation using finite mixture partial least squares. In Annals of Information Systems: Data Mining (pp. 19-49). Boston, MA: Springer US. https://doi.org/10.1007/978-1-4419-1280-0_2 
Roghanizad, M. M., \& Neufeld, D. J. (2015). Intuition, risk, and the formation of online trust. Computers in Human Behavior, 50, 489-498. https://doi.org/10.1016/j.chb.2015.04.025

Sarstedt, M., Becker, J.-M., Ringle, C. M., \& Schwaiger, M. (2011). Uncovering and treating unobserved heterogeneity with FIMIX-PLS: which model selection criterion provides an appropriate number of segments. Schmalenbach Business Review, 63(1), 34-62. https://doi.org/10.1007/BF03396886

Sarstedt, M., \& Ringle, C. M. (2010). Treating unobserved heterogeneity in PLS path modeling: a comparison of FIMIX-PLS with different data analysis strategies. Journal of Applied Statistics, 37(8), 1299-1318. https://doi.org/10.1080/02664760903030213

Shainesh, G. (2012). Effects of trustworthiness and trust on loyalty intentions. International Journal of Bank Marketing, 30(4), 267-279. https://doi.org/10.1108/02652321211236905

Shang, R.-A., Chen, Y.-C., \& Shen, L. (2005). Extrinsic versus intrinsic motivations for consumers to shop on-line. Information \& Management, 42(3), 401-413. https://doi.org/10.1016/j.im.2004.01.009

Sharma, S., Menard, P., \& Mutchler, L. A. (2017). Who to trust? Applying trust to social commerce. Journal of Computer Information Systems, 1-11. https://doi.org/10.1080/08874417.2017.1289356

Sheeran, P., \& Webb, T. L. (2016). The intention-behavior gap. Social and Personality Psychology Compass, 10(9), 503-518. https://doi.org/10.1111/spc3.12265

SIBS. (2017). SIBS Market report: digital commerce. Lisbon. Retrieved from https://www.sibs.pt/wp-content/uploads/sites/5/2017/02/SIBS-MARKET-REPORT_2016_PDF-INTERACTIVO_20170222.pdf

Stone, R. N., \& Grønhaug, K. (1993). Perceived risk: further considerations for the marketing discipline. European Journal of Marketing, 27(3), 39-50. https://doi.org/10.1108/03090569310026637

Sun, B., \& Morwitz, V. G. (2010). Stated intentions and purchase behavior: a unified model. International Journal of Research in Marketing, 27(4), 356-366. https://doi.org/10.1016/j.ijresmar.2010.06.001

Teo, T. S. H., \& Liu, J. (2007). Consumer trust in e-commerce in the United States, Singapore and China. Omega, 35(1), 22-38. https://doi.org/10.1016/j.omega.2005.02.001

Van Slyke, C., Bélanger, F., Johnson, R. D., \& Hightower, R. (2010). Gender-based differences in consumer e-commerce adoption. Communications of the Association for Information Systems, 26(1), Article 2.

Verhagen, T., \& van Dolen, W. (2009). Online purchase intentions: a multi-channel store image perspective. Information \& Management, 46(2), 77-82. https://doi.org/10.1016/j.im.2008.12.001

Wu, L.-Y., Chen, K.-Y., Chen, P.-Y., \& Cheng, S.-L. (2014). Perceived value, transaction cost, and repurchase-intention in online shopping: a relational exchange perspective. Journal of Business Research, 67(1), 2768-2776. https://doi.org/10.1016/j.jbusres.2012.09.007

Yang, Q., Pang, C., Liu, L., Yen, D. C., \& Michael Tarn, J. (2015). Exploring consumer perceived risk and trust for online payments: An empirical study in China's younger generation. Computers in Human Behavior, 50, 9-24. https://doi.org/10.1016/j.chb.2015.03.058

Zhang, W.-G., Zhang, Q., Mizgier, K. J., \& Zhang, Y. (2017). Integrating the customers' perceived risks and benefits into the triple-channel retailing. International Journal of Production Research, 55(22), 6676-6690. https://doi.org/10.1080/00207543.2017.1336679

Zhou, L., Dai, L., \& Zhang, D. (2007). Online shopping acceptance model - a critical survey of consumer factors in online shopping. Journal of Electronic Commerce Research, 8(1), 41-62.

Zhou, Z., Jin, X.-L., \& Fang, Y. (2014). Moderating role of gender in the relationships between perceived benefits and satisfaction in social virtual world continuance. Decision Support Systems, 65, 69-79. https://doi.org/10.1016/j.dss.2014.05.004 